\title{
Deciphering the Dichotomous Effects of PGC-1 $\alpha$ on Tumorigenesis and Metastasis
}

\author{
Simon-Pierre Gravel* \\ Laboratory of Metabolic Immunopharmacology, Faculty of Pharmacy, University of Montreal, Montreal, QC, Canada
}

Metabolic reprogramming confers cancer cells the ability to grow and survive under nutrient-depleted or stressful microenvironments. The amplification of oncogenes, the loss of tumor suppressors, as well as context- and lineage-specific determinants can converge and profoundly affect the metabolic status of cancer cells. Cumulating evidences suggest that highly glycolytic cells under the influence of oncogenes such as BRAF, or evolving in hypoxic microenvironments, will promote metastasis through modulation of multiple steps of tumorigenesis such as the epithelial-to-mesenchymal transition (EMT). On the contrary, increased reliance on mitochondrial respiration is associated with hyperplasic rather than metastatic disease. The PGC-1 $\alpha$ transcriptional coactivator, a master regulator of mitochondrial biogenesis, has recently been shown to exert antimetastatic effects in cancer, notably through inhibition of EMT. Besides,

OPEN ACCESS

Edited by:

Ala-Eddin Al Moustafa, Qatar University, Qatar

Reviewed by: Leonardo Freire-de-Lima, Universidade Federal do Rio de Janeiro, Brazil

Daniele Vergara,

University of Salento, Italy

${ }^{*}$ Correspondence: Simon-Pierre Gravel sp.grave/@umontreal.ca

Specialty section:

This article was submitted to Molecular and Cellular Oncology, a section of the journal Frontiers in Oncology

Received: 01 February 2018 Accepted: 06 March 2018 Published: 23 March 2018

Citation: Gravel S-P (2018) Deciphering the Dichotomous Effects of PGC- $1 \alpha$ on Tumorigenesis and Metastasis. Front. Oncol. 8:75. doi: 10.3389/fonc.2018.00075
PGC-1 $\alpha$ has the opposite role in specific cancer subtypes, in which it appears to provide growth advantages. Thus, the regulation and role of PGC-1 $\alpha$ in cancer is not univocal, and its use as a prognostic marker appears limited given its highly dynamic nature and its multifaceted regulation by transcriptional and posttranslational mechanisms. Herein, we expose key oncogenic and lineage-specific modules that finely regulate PGC-1 $\alpha$ to promote or dampen the metastatic process. We propose a unifying model based on the systematic analysis of its controversial implication in cancer from cell proliferation to EMT and metastasis. This short review will provide a good understanding of current challenges associated with the study of PGC- $1 \alpha$.

Keywords: PGC-1, cancer, metastasis, OXPHOS, oncogenes, tumor suppressors, microenvironment, reactive oxygen species

\section{INTRODUCTION}

Deregulated metabolism is now a well-documented hallmark of cancer cells that provides them with the ability to grow and survive under nutrient-depleted or stressful microenvironments $(1,2)$. Metabolic reprogramming is associated with important aspects of oncogenesis such as the epithelial-to-mesenchymal transition (EMT), a complex process that allows cancer cells to invade surrounding tissues and migrate to the vasculature (3-8). Oncogenes such as BRAF and MYC, through multifaceted shaping of central carbon metabolism and mitochondrial activity, can dictate the propensity of cancer cells to rely on specific metabolic routes such as glycolysis and glutaminolysis, thus revealing susceptibilities to metabolic drugs (9-13). While a preferential reliance on aerobic glycolysis (Warburg effect) instead of mitochondrial respiration has long been linked to increased tumor burden and poor outcome, it is now recognized that mitochondria have additional key roles in tumorigenesis and represent potential therapeutic targets (14-16). 
Mitochondrial biogenesis and function are under the tight control of the peroxisome proliferator-activated receptor- $\Upsilon$ coactivator-1 (PGC-1) family of transcriptional coactivators, among which, PGC- $1 \alpha$ has been the most extensively studied member $(17,18)$. PGC-1 $\alpha$ exerts its function through molecular scaffolding of diverse members of the nuclear receptors family, transcription factors, the TRAP/mediator complex, as well as various acetyl/methyltransferase complexes $(19,20)$. The magnitude and specificity of PGC-1 $\alpha$-directed transcriptional programs can be achieved through at least three distinct mechanisms: (1) by modulation of its expression level, thus limiting the recruitment of binding partners, (2) by the availability and functional status of its binding partners, and (3) by posttranslational modifications, which can modify both its expression level and the nature of its interactions (21-23). Hence, the complex regulation of PGC- $1 \alpha$ is function of the cellular landscape associated with a given context, which makes this coactivator a master integrator of the nutritional and redox statuses, cellular stress, infection, and oncogenic signaling. Given its intrinsic capacities to orchestrate cellular bioenergetics, it is not surprising that PGC-1 $\alpha$ is a key player in a variety of systems including muscular physiology, aging, and neurological functions $(24,25)$.

Besides its well-established functions as a master regulator of mitochondrial biogenesis and respiration, PGC- $1 \alpha$ has been shown to regulate many other processes that could be linked to oncogenesis. First, PGC- $1 \alpha$ conjointly promotes the expression of antioxidant genes that will protect cells from the deleterious effects of reactive oxygen species (ROS) as byproducts of the electron transport chain $(26,27)$. Second, PGC- $1 \alpha$ can modulate the expression of VEGF, a key player in inflammation and angiogenesis (28). While promoting catabolism of glucose and fatty acids in line with increased mitochondrial mass, PGC- $1 \alpha$ can also promote gluconeogenesis and lipogenesis, and thus could exert opposite anabolic functions (29-32). This apparent contradiction in PGC- $1 \alpha$ functions, which could be explained by context-specific determinants, is key to the understanding of its dichotomous effects on cancer development. Although PGC$1 \alpha$ could be considered at first as a potential tumor suppressor by promoting mitochondrial oxidation and opposing aerobic glycolysis, recent studies revealed that its role in tumorigenesis and metastasis is not univocal. In the following sections, we will present evidences associating both pro- and anti-tumorigenic roles of PGC-1 $\alpha$ and will provide a unifying model based on multifactorial determinants that shape its role in cancer.

\section{DICHOTOMOUS EFFECTS OF PGC-1 $\alpha$ ON ONCOGENESIS}

\section{PGC-1 $\alpha$ as a Prognostic Marker}

The association between PGC- $1 \alpha$ levels and disease-free survival in humans revealed that its sole expression is not necessarily predictive of outcome (33). While low PGC-1 $\alpha$ levels have been associated with poor outcome in breast, prostate, and VHLdeficient clear renal cell carcinoma (34-36), high PGC- $1 \alpha$ levels have also been associated with poor outcome in the context of melanoma, breast, and prostate cancer (37-40), revealing that other factors such as tumor heterogeneity and context-specific transcriptional programs are critical determinant of the implication of PGC- $1 \alpha$ in disease progression. Importantly, PGC- $1 \alpha$ levels do not necessarily follow the ones of OXPHOS genes in disease progression (41), suggesting that its regulation through posttranslational modification is underevaluated in the context of cancer research. There is currently limited evidence that genomic alterations of the PPARGC1A gene can be associated with disease outcome. Mutations in the PPARGC1A gene have been detected $(42,43)$, a specific polymorphism (Thr612Met) has been associated with some classes of breast cancer (44), and numerous polymorphisms have been linked to ovarian cancer susceptibility (45). While PPARGC1A amplification appears to be a rare event (38), important shallow deletions of PPARGC1A have been found in metastasis derived from prostate cancer in human studies (36). This intriguing observation suggests that selective pressure can diminish PGC- $1 \alpha$ levels, which could confer specific advantages to subsets of cells through the course of tumor evolution. Taken together, these studies suggest that the contribution of PGC- $1 \alpha$ on disease progression will be function of tumor history and cancer subtypes, and thus do not support its sole use as a prognostic marker for cancer medicine. In order to get a better understanding of the dualistic nature of PGC- $1 \alpha$ in cancer development, we surveyed the literature and evaluated the impact of PGC- $1 \alpha$ experimental manipulation on key aspects of disease progression such as cancer cell proliferation, primary tumor growth, ROS detoxification, the modulation of EMT, and metastasis. From these studies, it can be concluded that both high and low PGC- $1 \alpha$ levels in primary tumor can potentially lead to metastatic disease, which can be easily explained by the oncogenic landscape and context-specific determinants within the primary tumor (Figure 1).

\section{PGC-1 $\alpha$ and Mitochondrial Function}

Strikingly, independently of the final outcome that PGC- $1 \alpha$ has on oncogenesis, all examined studies fully support its classic role as a positive regulator of mitochondrial biogenesis and mitochondrial respiration in cancer cells $(31,35,38-40,46-54)$. This suggests that the dichotomous aspect of PGC- $1 \alpha$ on cancer must take root in other aspects of cancer development that could be differentially regulated by PGC-1 $\alpha$. These aspects will be developed in the following sections.

\section{Cellular Growth Is Conditioned by the Microenvironment}

Opposite to its uniform impact on mitochondrial function, PGC- $1 \alpha$ has divergent outcomes on cell proliferation and tumor growth, which can be largely explained by cancer type. For example, elevated PGC-1 $\alpha$ expression impairs clear renal cell carcinoma and prostate cancer cell lines proliferation and their ability to form tumors $(35,36)$, while it does the inverse in a subset of melanoma cells (38). Besides, the impact of PGC- $1 \alpha$ expression on cancer cell proliferation does not necessarily correlate with the growth of primary tumors established with the same cell lines $(31,50,55)$. An explanation for these discrepancies is that in vitro culture conditions are not representative 


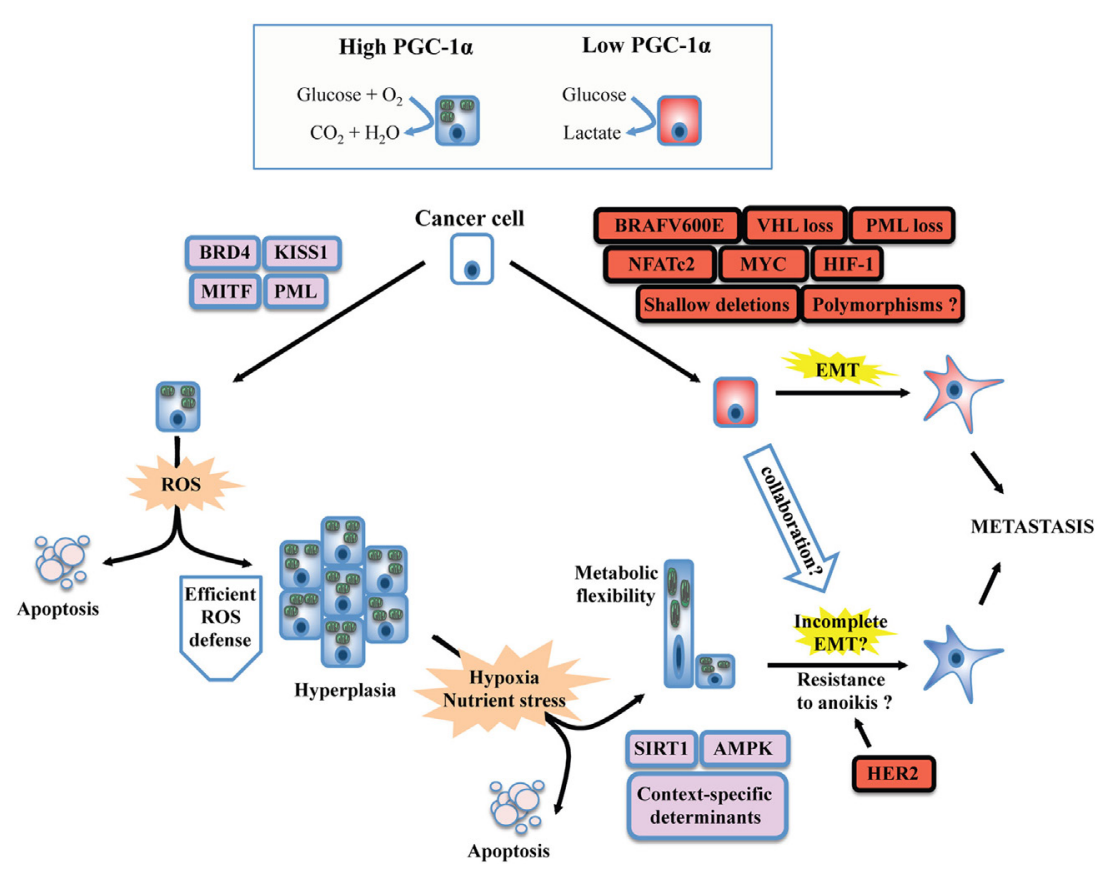

FIGURE 1 | Unifying model for the dichotomous effects of PGC-1 $\alpha$ on tumorigenesis and metastasis. PGC-1 $\alpha$ status usually reflects the metabolic profile of cancer cells. High PGC-1 $\alpha$ will promote mitochondrial metabolism and OXPHOS, while low PGC-1 $\alpha$ is usually associated with increased glycolysis. The switch between glycolytic and OXPHOS status will be the result of a complex interplay between oncogenes, tumor suppressor, and context-dependent determinants such as lineage-specific proteins. BRAF mutants, MYC amplification, and the loss of tumor suppressors such as VHL will downregulate PGC-1 $\alpha$ and will confer a glycolytic phenotype in line with the establishment of the epithelial-to-mesenchymal transition (EMT). Besides, context-specific proteins such as microphtalmia-associated transcription factor (MITF, melanocyte lineage) or KISS1 will promote PPARGC1A transcription or PGC-1 $\alpha$ protein stabilization, respectively. The emergence of metastasis in situations of high PGC-1 $\alpha$ despite its inhibitory role on EMT suggests that PGC-1 $\alpha$ will confer selective advantage to cancer cells evolving in specific contexts. Increased OXPHOS due to PGC-1 $\alpha$ activity will generate reactive oxygen species (ROS). To overcome this stress, an efficient antioxidant gene expression program must be induced, which will depend on the activity of PGC-1 $\alpha$ itself, the functionality, and availability of its transcriptional partners, as well as other context-dependent regulators. High PGC-1 $\alpha$ has been linked to increased tumor growth (hyperplasia), but not necessarily to promote metastasis. The selective pressure imposed to cancer cells by the tumor microenvironment will favor the survival of well-adapted cells, likely through the regulation of PGC-1 $\alpha$ by SIRT1 and AMP kinase (AMPK), as well as other context-specific factors. Notably, high PGC-1 $\alpha$ expression in specific cancer cells can generate metabolic hybrids (both OXPHOS and glycolytic), making these cells particularly flexible. Given that metastatic and circulating tumor cells with high PGC-1 $\alpha$ levels have been detected, several mechanisms could explain the propensity of some high PGC-1 $\alpha$ cells to metastasize. First, the completeness of EMT is not mandatory. Second, contextspecific oncogenes such as the HER2 receptors could increase survival upon cellular matrix detachment (anoikis). Third, glycolytic cells (low PGC-1 $\alpha$ ) could collaborate in the migration and invasion process of high PGC-1 $\alpha$ cells through the release of tissue remodeling factors. Finally, the growth advantages conferred by PGC-1 $\alpha$ might increase cancer cell survival and growth at distant metastatic niches, in spite of their low metastatic potential.

of the microenvironment experienced by cancer cells in vivo, which suggests that elevated PGC-1 $\alpha$ expression might provide growth advantage in vivo, notably by increasing glucose uptake or by promoting the use of glutamine to support mitochondrial respiration and lipogenesis $(31,32,50)$. Interestingly, a recent study revealed that PGC-1 $\alpha$ potentiates bioenergetics capacity and fuel flexibility of cancer cells (56). Thus, the development of appropriate in vitro culture conditions that better mimic the tumor microenvironment will be required to further determine which metabolic processes are selectively modulated by PGC- $1 \alpha$ to confer growth advantage (57).

\section{Cell Survival Is Function of ROS Detoxification}

In specific models, the growth-suppressive effects of PGC- $1 \alpha$ could be attributed to its capacity to induce apoptosis $(47,48,58)$, to increase ROS production, and DNA damage response (35), and to block cell cycle progression (36). One explanation for these unexpected findings is that PGC- $1 \alpha$ overexpression can lead to dramatic imbalance between ROS production by the electron transport chain and ROS detoxification, both orchestrated by PGC-1 $\alpha$ (27). Some cell lines might respond well to increased PGC-1 $\alpha$ input, while others might be unable to mount a proper antioxidant gene program due to differential availability of transcriptional partners or effectors. Only one study systematically measured the impact of PGC-1 $\alpha$ overexpression and knockdown on a panel of antioxidant genes, confirming that it can indeed promote ROS detoxification in a subset of melanoma cells (38).

\section{OXPHOS and Glycolysis Are Modulators of EMT}

A novel link between PGC- $1 \alpha$ and the inhibition of the EMT gene expression program is emerging and supports its tumor suppressive functions. Indeed, PGC- $1 \alpha$ has been shown to positively regulate the expression of the epidermal marker E-cadherin and inhibit the expression of multiple genes within the integrin/ 
TGF $\beta /$ WNT pathways $(49,59-61)$. There is now strong evidence that metabolic changes associated with cancer, such as mitochondrial dysfunction and increased glycolysis, efficiently promote EMT activation (6), which is in agreement with the notion that PGC- $1 \alpha$ antagonizes EMT. Moreover, OXPHOS downregulation is associated with low survival in most human cancers and shows negative correlation with EMT (41). To reconcile these facts with the observation that PGC- $1 \alpha$ can indeed promote metastasis (39, 56), context-specific and spatiotemporal regulation of PGC- $1 \alpha$ must be taken into account. Notably, tumor cells can exhibit wide differences in the completeness of their EMT program and still be able to invade (62). Also, PGC-1 $\alpha$ expression and functional status (acetylation, phosphorylation) is likely highly heterogeneous within a given tumor according to its highly dynamic expression (61). Thus, its inhibitory effect on EMT might be transient, bypassed by context-specific oncogenes, or influenced by neighbor cells. It will be important to determine how cells expressing high and low levels of PGC-1 $\alpha$ can coexist within a tumor and if they can collaborate during EMT. Finally, very limited studies systematically evaluated the impact of PGC- $1 \alpha$ on VEGF production, angiogenesis, and anchorage-independent growth. Therefore, it would be too early to conclude that PGC- $1 \alpha$ can indeed directly regulates these important tumorigenesis steps.

\section{ONCOGENIC AND LINEAGE-SPECIFIC REGULATION OF PGC-1 $\alpha$}

As stated above, the apparent dichotomous effects that PGC- $1 \alpha$ has on many steps of tumorigenesis are mostly explained by context-specific considerations. Recent literature revealed that the expression of PGC-1 $\alpha$ is under the tight control of oncogenes, tumor, and metastasis suppressors, as well as lineage-specific determinants (Figure 2). The study of melanoma provided important insights into both oncogenic and cell-lineage regulation of PGC-1 $\alpha$ (Figure 2, top left). Microphtalmia-associated transcription factor (MITF), a transcription factor whose expression is largely restricted to the melanocytic lineage, has been shown to be amplified in 30\% melanomas and required for survival of a subset of melanomas (63). MITF directly binds the PGC- $1 \alpha$ promoter and regulates the expression of mitochondrial genes $(37,38)$. Interestingly, PGC- $1 \alpha$ has been shown to regulate MITF expression in melanocytes (64), suggesting that a possible feed-forward mechanism might also occur in melanomas. Additional mechanisms by which PGC- $1 \alpha$ is positively regulated in melanoma are through KISS1-mediated increase in protein stabilization (65) and through direct transcriptional regulation by BRD4 (66). In melanoma, the differential impact of PGC- $1 \alpha$ on tumorigenesis appears to be associated with specific melanoma subsets. While PGC- $1 \alpha$ is essential to support mitochondrial respiration and survival in MITF-expressing cells (38), PGC- $1 \alpha$ can also block melanoma progression by at least two distinct mechanisms. First, PGC- $1 \alpha$ can directly regulate the expression of inhibitors of DNA binding (ID) proteins 2 and 3 that suppress TCF4, a major regulator of EMT and metastatic programs (61). Second, PGC- $1 \alpha$ and hypoxia-inducible factor $1 \alpha$ (HIF-1 $\alpha$ ) were shown to inversely correlate through a ROS-dependent mechanism (67). Given that the interplay between HIF- $1 \alpha$ and PGC- $1 \alpha$ is not fully elucidated $(28,68)$, and that HIF- $1 \alpha$ has major functions in tumorigenesis and metastasis $(69,70)$, it would be important to determine how HIF- $1 \alpha$ can influence the outcome of PGC- $1 \alpha$ in other cancer models. Importantly, the MIFT-PGC- $1 \alpha-\mathrm{ID} 2 / 3$ axis in under the control of the BRAF (V600E) oncogene, the most frequent BRAF mutation in melanoma. Mechanistically, BRAF appears to inhibit MITF transcription through ERK activation (37). In addition, NFATc2, a transcription factor activated by oncogenic BRAF (71), was recently identified as a potent suppressor of MITF-PGC- $1 \alpha$ in melanoma cells (72). Thus, multiples pathways under the control of BRAF might converge to oppose PGC-1 $\alpha$ and OXPHOS in subsets of melanoma.

The study of PGC- $1 \alpha$ in prostate cancer revealed a completely different regulatory landscape (Figure 2, top right). Prostate cancer is also a highly heterogeneous disease in which PGC-1 $\alpha$ appear to have dualistic functions $(36,73)$. PGC- $1 \alpha$ expression is lost during disease progression, notably by genomic deletions, which suppresses a gene expression program mediated by PGC- $1 \alpha$ and by the nuclear receptor estrogen-relator receptor $\alpha$ (36). Besides, PGC- $1 \alpha$ expression is enriched in a subset of prostate cancer patients in late disease stages (52). Importantly, two mechanisms that could potentially regulate PGC- $1 \alpha$ in prostate cancer rely on AMP kinase (AMPK) and the sirtuin SIRT1. AMPK and SIRT1 are sensors of metabolic stress that will, respectively, phosphorylate and deacetylate PGC- $1 \alpha$ in order to promote its transactivating functions (74). Strikingly, both proteins have been recognized for their dualistic contribution to cancer $(75,76)$, suggesting that the context-specific dualism of PGC- $1 \alpha$ might correlate with AMPK or SIRT1 statuses. Mechanistically, the androgen receptor, which is required for prostatic cancer cell growth and survival, is able to modulate PGC- $1 \alpha$ through CAMKK $\beta$ kinase and AMPK (52). Besides, the promyelocytic leukemia (PML) gene encodes for a tumor suppressor protein that potentiates PGC- $1 \alpha$ deacetylation through SIRT1, thus promoting bioenergetics and protection against anoikis in breast cancer (77). Interestingly, PML is frequently co-deleted with PTEN in metastatic prostate cancer (78), suggesting that PML loss could modulate PGC- $1 \alpha$ in prostate cancer through SIRT1. Moreover, PGC- $1 \alpha$ mediates the pro-metastatic functions of SIRT1 in other cancers such as hepatocellular carcinoma (40), further strengthening the importance of the SIRT1-PGC-1 $\alpha$ axis in cancer.

Finally, other PGC-1 $\alpha$ regulatory modules have been described for renal cell carcinoma (Figure 2, bottom left) and pancreatic ductal carcinoma (Figure 2, bottom right). These studies revealed that PGC- $1 \alpha$ expression can be downregulated by HIF- $1 \alpha$-mediated gene transcription of Dec1 (35) and by the MYC oncogene through direct binding of the PPARGC1A promoter (53). In both cases, the ratios of PGC- $1 \alpha$ to HIF- $1 \alpha$ or MYC function as rheostats that will dictate the propensity of cancer cells to rely on glycolysis or OXPHOS for survival. Hence, therapeutic strategies targeting the BRAF oncogene, HIF- $1 \alpha$, or MYC will promote PGC- $1 \alpha$-dependent mitochondrial biogenesis and will favor OXPHOS addiction, thus revealing vulnerabilities to metabolic agents such as biguanides that target complex I of the electron transport chain (79). Moreover, recent studies unveiled additional determinants of PGC- $1 \alpha$ expression in breast cancer. 


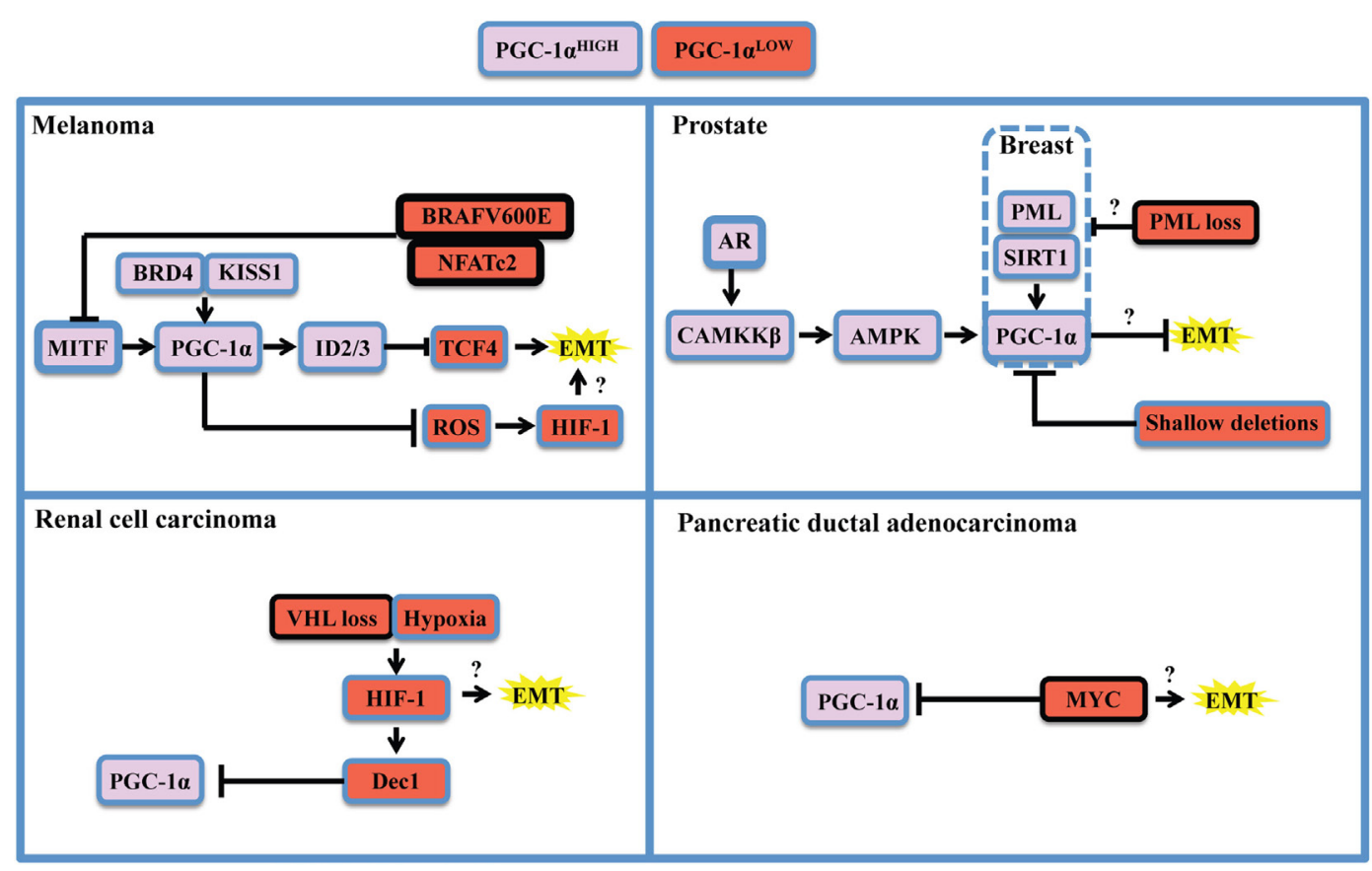

FIGURE 2 | Oncogenic and context-specific determinants that modulate PGC-1 $\alpha$ in cancer. The expression of PGC-1 $\alpha$ is influenced by the presence of oncogenes, the loss or dysfunction of tumor suppressors, and the expression of lineage-specific regulators. Context-specific regulation depends on the expression of lineage-specific modulators, such as microphtalmia-associated transcription factor (MITF) in melanoma, or the expression of the androgen receptor (AR) in prostate cancer. It is also function of cellular stresses, such as limitation in nutrient supply, hypoxia, and redox state, and will depend on the activity of the SIRT1 deacetylase and the AMP kinase (AMPK) that will potentiate PGC-1 $\alpha$ transactivating functions and might modify its gene expression programs. The oncogenic landscape [BRAF mutation, MYC amplification, VHL, or promyelocytic leukemia (PML) loss] will regulate PGC-1 $\alpha$ expression at the transcriptional level, likely through direct binding of transcriptional inhibitors to the PPARGC1A promoter. Cumulating evidences support the notion that PGC-1 $\alpha$ and mitochondrial OXPHOS are antagonistic to the establishment of the epithelial-to-mesenchymal transition (EMT). One mechanism supporting the inhibitory role of PGC-1 $\alpha$ on EMT is through induction of Inhibitors of DNA binding (ID) proteins 2 and 3 that suppress TCF4, an important modulator of EMT. Therefore, oncogenic signaling could relieve EMT inhibition by downregulating PGC-1 $\alpha$ and OXPHOS. By suppressing reactive oxygen species (ROS) though transcriptional regulation of antioxidant genes, PGC-1 $\alpha$ exerts antagonistic effects on hypoxia-inducible factor $1 \alpha(\mathrm{HIF-1 \alpha})$. These findings converge to delineate the existence of critical rheostats opposing the expression of PGC-1 $\alpha$ to the one of oncogenes and pro-glycolytic transcription factors such as HIF-1 $\alpha$. Question marks underline unknown links in the specified cancers in the context of PGC- $1 \alpha$ modulation.

Mitochondrial mass and PGC-1 $\alpha$ expression are controlled by $\beta$-catenin in estrogen receptor positive breast cancer cells (80). Interestingly, PGC- $1 \alpha$ expression is higher in the HER2+ and basal breast cancer subtypes, both associated with lower survival (32). It would be relevant to further characterize the interplay between HER 2 and the capacity of PGC- $1 \alpha$-expressing cells to metastasize, given pleiotropic roles of this oncogenic receptor in breast cancer metastasis (81-83).

\section{CONCLUSION}

To summarize, it is now appreciated that diverse oncogenic and lineage- and context-specific determinants can potentially modulate PGC- $1 \alpha$ expression and function in cancer. For a given cancer, assessment of PGC- $1 \alpha$ status to predict outcome seems insufficient without an exhaustive documentation on these critical determinants. Here, we presented different key mechanisms that explain the dualist impact of PGC- $1 \alpha$ on cancer progression. A key idea emerging from recent literature is that while PGC- $1 \alpha$ and mitochondrial OXPHOS usually suppress the metastatic process, PGC-1 $\alpha$ might still provide growth advantage in vivo by modulating other pathways in a context-dependent manner. Besides its regulation through sensing of various cellular stresses, its expression level and activity might be highly dynamic and heterogeneous during tumor evolution. Therefore, the survival of cancer cells and their ability to metastasize will be function of selective pressure dictated by the tumor microenvironment. Hence, systematic evaluation of oncogenes and context-specific determinants will undoubtedly contribute to expand our understanding of PGC- $1 \alpha$ function within a given context and will pave the way to the development of new prognostic marker combinations and new therapeutic strategies.

\section{AUTHOR CONTRIBUTIONS}

S-PG wrote the manuscript, designed, and prepared the figures.

\section{ACKNOWLEDGMENTS}

The author is grateful to Caroline Thivierge for critical reading and feedback. This work was supported by laboratory start-up funds from the Faculty of pharmacy, University of Montreal. 


\section{REFERENCES}

1. Hanahan D, Weinberg RA. Hallmarks of cancer: the next generation. Cell (2011) 144(5):646-74. doi:10.1016/j.cell.2011.02.013

2. Vander Heiden MG, DeBerardinis RJ. Understanding the intersections between metabolism and cancer biology. Cell (2017) 168(4):657-69. doi:10.1016/ j.cell.2016.12.039

3. Kalluri R, Weinberg RA. The basics of epithelial-mesenchymal transition. J Clin Invest (2009) 119(6):1420-8. doi:10.1172/JCI39104

4. Chaffer CL, San Juan BP, Lim E, Weinberg RA. EMT, cell plasticity and metastasis. Cancer Metastasis Rev (2016) 35(4):645-54. doi:10.1007/s10555016-9648-7

5. Nieto MA, Huang RY, Jackson RA, Thiery JP. Emt: 2016. Cell (2016) 166(1):21-45. doi:10.1016/j.cell.2016.06.028

6. Sciacovelli M, Frezza C. Metabolic reprogramming and epithelial-tomesenchymal transition in cancer. FEBS J (2017) 284(19):3132-44. doi:10.1111/ febs. 14090

7. Skrypek N, Goossens S, De Smedt E, Vandamme N, Berx G. Epithelial-tomesenchymal transition: epigenetic reprogramming driving cellular plasticity. Trends Genet (2017) 33(12):943-59. doi:10.1016/j.tig.2017.08.004

8. Brabletz T, Kalluri R, Nieto MA, Weinberg RA. EMT in cancer. Nat Rev Cancer (2018) 18(2):128-34. doi:10.1038/nrc.2017.118

9. Stine ZE, Walton ZE, Altman BJ, Hsieh AL, Dang CV. MYC, metabolism, and cancer. CancerDiscov (2015) 5(10):1024-39. doi:10.1158/2159-8290.CD-15-0507

10. Nagarajan A, Malvi P, Wajapeyee N. Oncogene-directed alterations in cancer cell metabolism. Trends Cancer (2016) 2(7):365-77. doi:10.1016/ j.trecan.2016.06.002

11. Luengo A, Gui DY, Vander Heiden MG. Targeting metabolism for cancer therapy. Cell Chem Biol (2017) 24(9):1161-80. doi:10.1016/j.chembiol.2017.08.028

12. Martinez-Outschoorn UE, Peiris-Pages M, Pestell RG, Sotgia F, Lisanti MP. Cancer metabolism: a therapeutic perspective. Nat Rev Clin Oncol (2017) 14(1):11-31. doi:10.1038/nrclinonc. 2016.60

13. Ratnikov BI, Scott DA, Osterman AL, Smith JW, Ronai ZA. Metabolic rewiring in melanoma. Oncogene (2017) 36(2):147-57. doi:10.1038/onc.2016.198

14. Vyas S, Zaganjor E, Haigis MC. Mitochondria and cancer. Cell (2016) 166(3):555-66. doi:10.1016/j.cell.2016.07.002

15. Zong WX, Rabinowitz JD, White E. Mitochondria and cancer. Mol Cell (2016) 61(5):667-76. doi:10.1016/j.molcel.2016.02.011

16. Porporato PE, Filigheddu N, Bravo-San Pedro JM, Kroemer G, Galluzzi L. Mitochondrial metabolism and cancer. Cell Res (2018) 28(3):265-80. doi:10.1038/cr.2017.155

17. Villena JA. New insights into PGC-1 coactivators: redefining their role in the regulation of mitochondrial function and beyond. FEBS J (2015) 282(4):647-72. doi:10.1111/febs.13175

18. Luo C, Widlund HR, Puigserver P. PGC-1 coactivators: shepherding the mitochondrial biogenesis of tumors. Trends Cancer (2016) 2(10):619-31. doi:10.1016/j.trecan.2016.09.006

19. Wallberg AE, Yamamura S, Malik S, Spiegelman BM, Roeder RG. Coordination of p300-mediated chromatin remodeling and TRAP/mediator function through coactivator PGC-1alpha. Mol Cell (2003) 12(5):1137-49. doi:10.1016/ S1097-2765(03)00391-5

20. Aguilo F, Li S, Balasubramaniyan N, Sancho A, Benko S, Zhang F, et al. Deposition of 5-methylcytosine on enhancer RNAs enables the coactivator function of PGC-1alpha. Cell Rep (2016) 14(3):479-92. doi:10.1016/j.celrep. 2015.12.043

21. Fernandez-Marcos PJ, Auwerx J. Regulation of PGC-1alpha, a nodal regulator of mitochondrial biogenesis. Am J Clin Nutr (2011) 93(4):884S-90S. doi:10.3945/ajcn.110.001917

22. Lustig Y, Ruas JL, Estall JL, Lo JC, Devarakonda S, Laznik D, et al. Separation of the gluconeogenic and mitochondrial functions of PGC-1\{alpha\} through S6 kinase. Genes Dev (2011) 25(12):1232-44. doi:10.1101/gad.2054711

23. Adamovich Y, Shlomai A, Tsvetkov P, Umansky KB, Reuven N, Estall JL, et al. The protein level of PGC-1alpha, a key metabolic regulator, is controlled by NADH-NQO1. Mol Cell Biol (2013) 33(13):2603-13. doi:10.1128/ MCB.01672-12

24. Austin S, St-Pierre J. PGC1alpha and mitochondrial metabolism - emerging concepts and relevance in ageing and neurodegenerative disorders. J Cell Sci (2012) 125(Pt 21):4963-71. doi:10.1242/jcs.113662
25. Kupr B, Handschin C. Complex coordination of cell plasticity by a PGClalpha-controlled transcriptional network in skeletal muscle. Front Physio (2015) 6:325. doi:10.3389/fphys.2015.00325

26. Valle I, Alvarez-Barrientos A, Arza E, Lamas S, Monsalve M. PGC-1alpha regulates the mitochondrial antioxidant defense system in vascular endothelial cells. Cardiovasc Res (2005) 66(3):562-73. doi:10.1016/j.cardiores.2005. 01.026

27. St-Pierre J, Drori S, Uldry M, Silvaggi JM, Rhee J, Jager S, et al. Suppression of reactive oxygen species and neurodegeneration by the PGC-1 transcriptional coactivators. Cell (2006) 127(2):397-408. doi:10.1016/j.cell.2006.09.024

28. Arany Z, Foo SY, Ma Y, Ruas JL, Bommi-Reddy A, Girnun G, et al. HIFindependent regulation of VEGF and angiogenesis by the transcriptional coactivator PGC-1alpha. Nature (2008) 451(7181):1008-12. doi:10.1038/ nature 06613

29. Michael LF, Wu Z, Cheatham RB, Puigserver P, Adelmant G, Lehman JJ, et al. Restoration of insulin-sensitive glucose transporter (GLUT4) gene expression in muscle cells by the transcriptional coactivator PGC-1. Proc Natl Acad Sci U S A (2001) 98(7):3820-5. doi:10.1073/pnas.061035098

30. Li X, Monks B, Ge Q, Birnbaum MJ. Akt/PKB regulates hepatic metabolism by directly inhibiting PGC-1alpha transcription coactivator. Nature (2007) 447(7147):1012-6. doi:10.1038/nature05861

31. Bhalla K, Hwang BJ, Dewi RE, Ou L, Twaddel W, Fang HB, et al. PGC1alpha promotes tumor growth by inducing gene expression programs supporting lipogenesis. Cancer Res (2011) 71(21):6888-98. doi:10.1158/0008-5472.CAN11-1011

32. McGuirk S, Gravel SP, Deblois G, Papadopoli DJ, Faubert B, Wegner A, et al. PGC-1alpha supports glutamine metabolism in breast cancer. Cancer Metab (2013) 1(1):22. doi:10.1186/2049-3002-1-22

33. Deblois G, St-Pierre J, Giguere V. The PGC-1/ERR signaling axis in cancer. Oncogene (2013) 32(30):3483-90. doi:10.1038/onc.2012.529

34. Jiang WG, Douglas-Jones A, Mansel RE. Expression of peroxisome-proliferator activated receptor-gamma (PPARgamma) and the PPARgamma co-activator, PGC-1, in human breast cancer correlates with clinical outcomes. Int J Cancer (2003) 106(5):752-7. doi:10.1002/ijc.11302

35. LaGory EL, Wu C, Taniguchi CM, Ding CC, Chi JT, von Eyben R, et al. Suppression of PGC-1alpha is critical for reprogramming oxidative metabolism in renal cell carcinoma. Cell Rep (2015) 12(1):116-27. doi:10.1016/j.celrep. 2015.06.006

36. Torrano V, Valcarcel-Jimenez L, Cortazar AR, Liu X, Urosevic J, CastilloMartin M, et al. The metabolic co-regulator PGC1alpha suppresses prostate cancer metastasis. Nat Cell Biol (2016) 18(6):645-56. doi:10.1038/ncb3357

37. Haq R, Shoag J, Andreu-Perez P, Yokoyama S, Edelman H, Rowe GC, et al. Oncogenic BRAF regulates oxidative metabolism via PGC1alpha and MITF Cancer Cell (2013) 23(3):302-15. doi:10.1016/j.ccr.2013.02.003

38. Vazquez F, Lim JH, Chim H, Bhalla K, Girnun G, Pierce K, et al. PGC1alpha expression defines a subset of human melanoma tumors with increased mitochondrial capacity and resistance to oxidative stress. Cancer Cell (2013) 23(3):287-301. doi:10.1016/j.ccr.2012.11.020

39. LeBleu VS, O’Connell JT, Gonzalez Herrera KN, Wikman H, Pantel K, Haigis MC, et al. PGC-1alpha mediates mitochondrial biogenesis and oxidative phosphorylation in cancer cells to promote metastasis. Nat Cell Biol 16(10) (2014) 99(2-1003):1001-15. doi:10.1038/ncb3039

40. Li Y, Xu S, Li J, Zheng L, Feng M, Wang X, et al. SIRT1 facilitates hepatocellular carcinoma metastasis by promoting PGC-1alpha-mediated mitochondrial biogenesis. Oncotarget (2016) 7(20):29255-74. doi:10.18632/ oncotarget.8711

41. Gaude E, Frezza C. Tissue-specific and convergent metabolic transformation of cancer correlates with metastatic potential and patient survival. Nat Commun (2016) 7:13041. doi:10.1038/ncomms13041

42. Prickett TD, Agrawal NS, Wei X, Yates KE, Lin JC, Wunderlich JR, et al. Analysis of the tyrosine kinome in melanoma reveals recurrent mutations in ERBB4. Nat Genet (2009) 41(10):1127-32. doi:10.1038/ng.438

43. Stark MS, Woods SL, Gartside MG, Bonazzi VF, Dutton-Regester K, Aoude LG, et al. Frequent somatic mutations in MAP3K5 and MAP3K9 in metastatic melanoma identified by exome sequencing. Nat Genet (2011) 44(2):165-9. doi:10.1038/ng.1041

44. Wirtenberger M, Tchatchou S, Hemminki K, Schmutzhard J, Sutter C, Schmutzler RK, et al. Associations of genetic variants in the estrogen receptor 
coactivators PPARGC1A, PPARGC1B and EP300 with familial breast cancer. Carcinogenesis (2006) 27(11):2201-8. doi:10.1093/carcin/bgl067

45. Permuth-Wey J, Chen YA, Tsai YY, Chen Z, Qu X, Lancaster JM, et al. Inherited variants in mitochondrial biogenesis genes may influence epithelial ovarian cancer risk. Cancer Epidemiol Biomarkers Prev (2011) 20(6):1131-45. doi:10.1158/1055-9965.EPI-10-1224

46. Srivastava S, Barrett JN, Moraes CT. PGC-1alpha/beta upregulation is associated with improved oxidative phosphorylation in cells harboring nonsense mtDNA mutations. Hum Mol Genet (2007) 16(8):993-1005. doi:10.1093/ hmg/ddm045

47. D’Errico I, Lo Sasso G, Salvatore L, Murzilli S, Martelli N, Cristofaro M, et al. Bax is necessary for PGClalpha pro-apoptotic effect in colorectal cancer cells. Cell Cycle (2011) 10(17):2937-45. doi:10.4161/cc.10.17.16791

48. D’Errico I, Salvatore L, Murzilli S, Lo Sasso G, Latorre D, Martelli N, et al. Peroxisome proliferator-activated receptor-gamma coactivator 1-alpha (PGC1alpha) is a metabolic regulator of intestinal epithelial cell fate. Proc Natl Acad Sci U S A (2011) 108(16):6603-8. doi:10.1073/pnas.1016354108

49. Tiraby C, Hazen BC, Gantner ML, Kralli A. Estrogen-related receptor gamma promotes mesenchymal-to-epithelial transition and suppresses breast tumor growth. Cancer Res (2011) 71(7):2518-28. doi:10.1158/0008-5472. CAN-10-1315

50. Klimcakova E, Chenard V, McGuirk S, Germain D, Avizonis D, Muller WJ, et al. PGC-1alpha promotes the growth of ErbB2/Neu-induced mammary tumors by regulating nutrient supply. Cancer Res (2012) 72(6):1538-46. doi:10.1158/0008-5472.CAN-11-2967

51. Salem AF, Whitaker-Menezes D, Howell A, Sotgia F, Lisanti MP. Mitochondrial biogenesis in epithelial cancer cells promotes breast cancer tumor growth and confers autophagy resistance. Cell Cycle (2012) 11(22):4174-80. doi:10.4161/ cc. 22376

52. Tennakoon JB, Shi Y, Han JJ, Tsouko E, White MA, Burns AR, et al. Androgens regulate prostate cancer cell growth via an AMPK-PGC-1alpha-mediated metabolic switch. Oncogene (2014) 33(45):5251-61. doi:10.1038/onc.2013.463

53. Sancho P, Burgos-Ramos E, Tavera A, Bou Kheir T, Jagust P, Schoenhals M, et al. MYC/PGC-1alpha balance determines the metabolic phenotype and plasticity of pancreatic cancer stem cells. Cell Metab (2015) 22(4):590-605. doi:10.1016/j.cmet.2015.08.015

54. Lou C, Xiao M, Cheng S, Lu X, Jia S, Ren Y, et al. MiR-485-3p and miR-485-5p suppress breast cancer cell metastasis by inhibiting PGC-1alpha expression. Cell Death Dis (2016) 7:e2159. doi:10.1038/cddis.2016.27

55. Audet-Walsh E, Papadopoli DJ, Gravel SP, Yee T, Bridon G, Caron M, et al. The PGC-1alpha/ERRalpha axis represses one-carbon metabolism and promotes sensitivity to anti-folate therapy in breast cancer. Cell Rep (2016) 14(4):920-31. doi:10.1016/j.celrep.2015.12.086

56. Andrzejewski S, Klimcakova E, Johnson RM, Tabaries S, Annis MG, McGuirk S, etal.PGC-1alphapromotesbreastcancermetastasisand confersbioenergeticflexibilityagainstmetabolic drugs. Cell Metab (2017)26(5):778-87.e5. doi:10.1016/ j.cmet.2017.09.006

57. Gravel SP, Avizonis D, St-Pierre J. Metabolomics analyses of cancer cells in controlled microenvironments. Methods Mol Biol (2016) 1458:273-90. doi:10.1007/978-1-4939-3801-8_20

58. Zhang Y, Ba Y, Liu C, Sun G, Ding L, Gao S, et al. PGC-1alpha induces apoptosis in human epithelial ovarian cancer cells through a PPARgamma-dependent pathway. Cell Res (2007) 17(4):363-73. doi:10.1038/cr.2007.11

59. Lee HJ, Su Y, Lui WY, Chau GY, Yin PH, Lee HC, et al. Peroxisome proliferator-activated receptor gamma coactivator-1 alpha (PGC-1alpha) upregulated E-cadherin expression in HepG2 cells. FEBS Lett (2008) 582(5):627-34. doi:10.1016/j.febslet.2008.01.033

60. Lee HJ, Su Y, Yin PH, Lee HC, Chi CW. PPAR(gamma)/PGC-1(alpha) pathway in E-cadherin expression and motility of HepG2 cells. Anticancer Res (2009) 29(12):5057-63. Retreived from: http://ar.iiarjournals.org

61. Luo C, Lim JH, Lee Y, Granter SR, Thomas A, Vazquez F, et al. A PGC1alphamediated transcriptional axis suppresses melanoma metastasis. Nature (2016) 537(7620):422-6. doi:10.1038/nature19347

62. Drasin DJ, Robin TP, Ford HL. Breast cancer epithelial-to-mesenchymal transition: examining the functional consequences of plasticity. Breast Cancer Res (2011) 13(6):226. doi:10.1186/bcr3037

63. Garraway LA, Widlund HR, Rubin MA, Getz G, Berger AJ, Ramaswamy S, et al. Integrative genomic analyses identify MITF as a lineage survival oncogene amplified in malignant melanoma. Nature (2005) 436(7047):117-22. doi:10.1038/nature 03664

64. Shoag J, Haq R, Zhang M, Liu L, Rowe GC, Jiang A, et al. PGC-1 coactivators regulate MITF and the tanning response. Mol Cell (2013) 49(1):145-57. doi:10.1016/j.molcel.2012.10.027

65. Liu W, Beck BH, Vaidya KS, Nash KT, Feeley KP, Ballinger SW, et al. Metastasis suppressor KISS1 seems to reverse the Warburg effect by enhancing mitochondrial biogenesis. Cancer Res (2014) 74(3):954-63. doi:10.1158/00085472.CAN-13-1183

66. Gelato KA, Schockel L, Klingbeil O, Ruckert T, Lesche R, Toedling J, et al. Super-enhancers define a proliferative PGC-1alpha-expressing melanoma subgroup sensitive to BET inhibition. Oncogene (2018) 37(4):512-21. doi:10.1038/onc.2017.325

67. Lim JH, Luo C, Vazquez F, Puigserver P. Targeting mitochondrial oxidative metabolism in melanoma causes metabolic compensation through glucose and glutamine utilization. Cancer Res (2014) 74(13):3535-45. doi:10.1158/00085472.CAN-13-2893-T

68. O'Hagan KA, Cocchiglia S, Zhdanov AV, Tambuwala MM, Cummins EP, Monfared M, et al. PGC-1alpha is coupled to HIF-1alpha-dependent gene expression by increasing mitochondrial oxygen consumption in skeletal muscle cells. Proc Natl Acad Sci U S A (2009) 106(7):2188-93. doi:10.1073/pnas. 0808801106

69. Yang MH, Wu MZ, Chiou SH, Chen PM, Chang SY, Liu CJ, et al. Direct regulation of TWIST by HIF-1alpha promotes metastasis. Nat Cell Biol (2008) 10(3):295-305. doi:10.1038/ncb1691

70. Schito L, Semenza GL. Hypoxia-inducible factors: master regulators of cancer progression. Trends Cancer (2016) 2(12):758-70. doi:10.1016/j.trecan. 2016.10.016

71. Flockhart RJ, Armstrong JL, Reynolds NJ, Lovat PE. NFAT signalling is a novel target of oncogenic BRAF in metastatic melanoma. Br J Cancer (2009) 101(8):1448-55. doi:10.1038/sj.bjc.6605277

72. Perotti V, Baldassari P, Molla A, Vegetti C, Bersani I, Maurichi A, et al. NFATc2 is an intrinsic regulator of melanoma dedifferentiation. Oncogene (2016) 35(22):2862-72. doi:10.1038/onc.2015.355

73. Shiota M, Yokomizo A, Tada Y, Inokuchi J, Tatsugami K, Kuroiwa K, et al. Peroxisome proliferator-activated receptor gamma coactivator-1alpha interacts with the androgen receptor (AR) and promotes prostate cancer cell growth by activating the AR. Mol Endocrinol (2010) 24(1):114-27. doi:10.1210/me.2009-0302

74. Scarpulla RC, Vega RB, Kelly DP. Transcriptional integration of mitochondrial biogenesis. Trends Endocrinol Metab (2012) 23(9):459-66. doi:10.1016/ j.tem.2012.06.006

75. Song NY, Surh YJ. Janus-faced role of SIRT1 in tumorigenesis. Ann N Y Acad Sci (2012) 1271:10-9. doi:10.1111/j.1749-6632.2012.06762.x

76. Khan AS, Frigo DE. A spatiotemporal hypothesis for the regulation, role, and targeting of AMPK in prostate cancer. Nat Rev Urol (2017) 14(3):164-80. doi:10.1038/nrurol.2016.272

77. Carracedo A, Weiss D, Leliaert AK, Bhasin M, de Boer VC, Laurent G, et al. A metabolic prosurvival role for PML in breast cancer. J Clin Invest (2012) 122(9):3088-100. doi:10.1172/JCI62129

78. Chen M, Zhang J, Sampieri K, Clohessy JG, Mendez L, Gonzalez-Billalabeitia E, et al. An aberrant SREBP-dependent lipogenic program promotes metastatic prostate cancer. Nat Genet (2018) 50(2):206-18. doi:10.1038/s41588017-0027-2

79. Luengo A, Sullivan LB, Heiden MG. Understanding the complex-I-ty of metformin action: limiting mitochondrial respiration to improve cancer therapy. BMC Biol (2014) 12:82. doi:10.1186/s12915-014-0082-4

80. Vergara D, Stanca E, Guerra F, Priore P, Gaballo A, Franck J, et al. beta-Catenin knockdown affects mitochondrial biogenesis and lipid metabolism in breast cancer cells. Front Physiol (2017) 8:544. doi:10.3389/fphys.2017.00544

81. Schafer ZT, Grassian AR, Song L, Jiang Z, Gerhart-Hines Z, Irie HY, et al. Antioxidant and oncogene rescue of metabolic defects caused by loss of matrix attachment. Nature (2009) 461(7260):109-13. doi:10.1038/nature08268

82. Gupta P, Srivastava SK. HER2 mediated de novo production of TGFbeta leads to SNAIL driven epithelial-to-mesenchymal transition and metastasis of breast cancer. Mol Oncol (2014) 8(8):1532-47. doi:10.1016/j.molonc.2014.06.006

83. Rayavarapu RR, Heiden B, Pagani N, Shaw MM, Shuff S, Zhang S, et al. The role of multicellular aggregation in the survival of ErbB2-positive breast 
cancer cells during extracellular matrix detachment. J Biol Chem (2015) 290(14):8722-33. doi:10.1074/jbc.M114.612754

Conflict of Interest Statement: The author declares that the research was conducted in the absence of any commercial or financial relationships that could be construed as a potential conflict of interest.
Copyright $\odot 2018$ Gravel. This is an open-access article distributed under the terms of the Creative Commons Attribution License (CC BY). The use, distribution or reproduction in other forums is permitted, provided the original author(s) and the copyright owner are credited and that the original publication in this journal is cited, in accordance with accepted academic practice. No use, distribution or reproduction is permitted which does not comply with these terms. 